\title{
Brain renin-angiotensin system and dopaminergic cell vulnerability
}

\section{Jose L. Labandeira-García ${ }^{1,2}$ *, Pablo Garrido-Gil ${ }^{1,2}$, Jannette Rodriguez-Pallares ${ }^{1,2}$, Rita Valenzuela ${ }^{1,2}$, Ana Borrajo ${ }^{1,2}$ and Ana I. Rodríguez-Perez ${ }^{1,2}$}

\author{
Laboratory of Neuroanatomy and Experimental Neurology, Department of Morphological Sciences, CIMUS, Faculty of Medicine, University of Santiago de \\ Compostela, Santiago de Compostela, Spain \\ ${ }^{2}$ Networking Research Center on Neurodegenerative Diseases (CIBERNED), Madrid, Spain
}

\section{Edited by:}

Javier Blesa, Columbia University, USA

\section{Reviewed by:}

Tomas Gonzalez-Hernandez,

University of La Laguna, Spain

Farzad Mortazavi, Boston University

School of Medicine, USA

${ }^{*}$ Correspondence:

Jose L. Labandeira-García,

Laboratory of Neuroanatomy and

Experimental Neurology,

Department of Morphological

Sciences, CIMUS, Faculty of

Medicine, University of Santiago de

Compostela, Santiago de

Compostela 15782, Spain

e-mail: joseluis.labandeira@usc.es
Although the renin-angiotensin system (RAS) was classically considered as a circulating system that regulates blood pressure, many tissues are now known to have a local RAS. Angiotensin, via type 1 receptors, is a major activator of the NADPH-oxidase complex, which mediates several key events in oxidative stress (OS) and inflammatory processes involved in the pathogenesis of major aging-related diseases. Several studies have demonstrated the presence of RAS components in the basal ganglia, and particularly in the nigrostriatal system. In the nigrostriatal system, RAS hyperactivation, via NADPH-oxidase complex activation, exacerbates OS and the microglial inflammatory response and contributes to progression of dopaminergic degeneration, which is inhibited by angiotensin receptor blockers and angiotensin converting enzyme (ACE) inhibitors. Several factors may induce an increase in RAS activity in the dopaminergic system. A decrease in dopaminergic activity induces compensatory upregulation of local RAS function in both dopaminergic neurons and glia. In addition to its role as an essential neurotransmitter, dopamine may also modulate microglial inflammatory responses and neuronal OS via RAS. Important counterregulatory interactions between angiotensin and dopamine have also been observed in several peripheral tissues. Neurotoxins and proinflammatory factors may also act on astrocytes to induce an increase in RAS activity, either independently of or before the loss of dopamine. Consistent with a major role of RAS in dopaminergic vulnerability, increased RAS activity has been observed in the nigra of animal models of aging, menopause and chronic cerebral hypoperfusion, which also showed higher dopaminergic vulnerability. Manipulation of the brain RAS may constitute an effective neuroprotective strategy against dopaminergic vulnerability and progression of Parkinson's disease.

Keywords: aging, angiotensin, dopamine, NADPH-oxidase, neurodegeneration, neuroinflammation, oxidative stress, parkinson

\section{INTRODUCTION}

The renin-angiotensin system (RAS) was initially considered as a circulating humoral system, with functions in regulating blood pressure and in sodium and water homeostasis. The RAS is phylogenetically one of the oldest hormone systems. It has been suggested that the RAS played an important role in human evolution, and it is possible that our ancestors may have survived on little salt, thanks to RAS activation (Lev-Ran and Porta, 2005). Angiotensin II (AII), which is the most important effector peptide of the RAS, is formed by the sequential action of two enzymes -renin and angiotensin converting enzyme (ACE)- on the precursor glycoprotein angiotensinogen. The actions of AII are mediated by two main cell receptors: AII type 1 and 2 (AT1 and AT2) receptors (Unger et al., 1996; Oro et al., 2007; Jones et al., 2008). In addition to the afore mentioned components of the RAS, several other components that are involved in secondary mechanisms of this system have emerged (Cuadra et al., 2010; Wright and Harding, 2013). The AT1 receptor mediates most of the classical peripheral actions of AII. It is generally considered that AT2 receptors exert actions directly opposed to those mediated by AT1 receptors thus antagonizing many of the effects of the latter (Chabrashvili et al., 2003; Jones et al., 2008). However, the relationships between AT1 and AT2 are probably more complex and remain to be fully clarified.

\section{THE LOCAL (TISSUE OR PARACRINE) RAS. ROLE IN OXIDATIVE STRESS, INFLAMMATION AND TISSUE DEGENERATION}

It is now known that, in addition to the "classical" humoral RAS, many tissues have local (tissue or paracrine) RAS that contain the different components previously described for the circulating RAS (Ganong, 1994; Re, 2004). Although both circulating 
RAS and local RAS act together in different tissues, it is generally accepted that circulating components are far less important than local formation of angiotensins for functioning of the system. Abnormal upregulation of local AII induces oxidative stress (OS) damage and exacerbates of inflammation. AII is a major activator of the NADPH-oxidase complex (Zalba et al., 2001; Touyz, 2004; Hoogwerf, 2010) which is the most important intracellular source of reactive oxygen species (ROS) other than mitochondria (Babior, 1999, 2004; Cai, 2005). It is known that NADPH-dependent oxidases are upregulated in major agingrelated diseases such as hypertension, diabetes and atherosclerosis (Griendling et al., 2000; Münzel and Keany, 2001). It is usually considered that activation of AT2 receptors inhibits NADPHoxidase activation and counteracts the deleterious effects of AT1 activation. In peripheral tissues, the upregulated AII acts, via AT1 receptors, on the resident cells (i.e., endothelial cells, smooth muscle cells) leading to OS, and subsequent production of chemokines, cytokines, and adhesion molecules, which contribute to the migration of inflammatory cells into the injured tissue (Ruiz-Ortega et al., 2001; Suzuki et al., 2003). Furthermore, AII acts on inflammatory cells to induce inflammatory responses and to release high levels of ROS mainly by activation of the NADPH complex (Okamura et al., 1999; Yanagitani et al., 1999; Qin et al., 2004; Touyz, 2004).

Finally, in addition to the "classical" humoral RAS and the local or tissue RAS, a number of recent studies support the existence of third level of RAS in several types of cells (Baker et al., 2004): the intracellular or intracrine RAS. The existence of functional intracellular RAS opens up new perspectives for understanding the effects of the RAS and for the management of RAS-related diseases (Kumar et al., 2007, 2009).

\section{THE BRAIN RAS. LOCAL RAS IN THE NIGROSTRIATAL DOPAMINERGIC SYSTEM}

The role of the RAS on brain function was initially associated with effects of the circulating RAS in areas involved in the central control of blood pressure and sodium and water homeostasis, which are located in circumventricular organs lacking the blood-brain barrier (von Bohlen und Halbach and Albrecht, 2006; Phillips and de Oliveira, 2008). However, over the last two decades, all components of the classical RAS have been identified in different brain areas inside the blood-brain barrier, and the brain RAS has been suggested to be involved in additional functions and disorders (Kerr et al., 2005; Maul et al., 2005; Saavedra, 2005; Saab et al., 2007). Interestingly, it has been observed that brain levels of AII are much higher than circulating levels (Hermann et al., 1984), and that the precursor protein angiotensinogen is mainly produced by astrocytes (Stornetta et al., 1988; Milsted et al., 1990), although it is also produced at low levels in neurons (Kumar et al., 1988; Thomas et al., 1992). Major components involved in the effects of AII in peripheral tissues such as NADPHoxidases have also been located in neurons (Noh and Koh, 2000; Wang et al., 2004) and glial cells (Gao et al., 2003; Wu et al., 2003). Several studies have shown that, as previously observed in peripheral organs, AT1 receptor blockers and ACE inhibitors (ACEIs) decreased the inflammatory response in the CNS (Platten et al., 2009; Stegbauer et al., 2009; Saavedra, 2012). In accordance with their inhibitory effect on brain inflammation, beneficial effects of AT1 inhibition have been observed in a number of processes mediated by microglial activation and neuroinflammation, including animal models of Alzheimer's disease (Kehoe and Wilcock, 2007; Mogi and Horiuchi, 2009), brain ischemia (Lou et al., 2004; Iwanami et al., 2010) and multiple sclerosis (Platten et al., 2009; Stegbauer et al., 2009).

Several studies have reported the presence of RAS components in the basal ganglia, particularly in the nigrostriatal system (Quinlan and Phillips, 1981; Simonnet et al., 1981; Brownfield et al., 1982; Chai et al., 1987; Allen et al., 1992). In recent studies (Rodriguez-Pallares et al., 2008; Joglar et al., 2009; Valenzuela et al., 2010; Garrido-Gil et al., 2013b), we used laser confocal microscopy and other methods to demonstrate the presence of AT1 and AT2 receptors in nigral dopaminergic neurons and glial cells (i.e., astrocytes and microglia) in rodents and primates, including humans (Garrido-Gil et al., 2013b), as well as in primary mesencephalic cell cultures (Rodriguez-Pallares et al., 2004, 2008; Joglar et al., 2009). Furthermore, we demonstrated the presence of different cytoplasmatic and membrane subunits of the NADPH complex in mesencephalic dopaminergic neurons, astrocytes and microglia (Rodriguez-Pallares et al., 2007, 2008; Joglar et al., 2009). Recently, we have described, for the first time, prorenin receptors in nigral dopaminergic neurons and microglial cells in humans, monkeys and rats (Valenzuela et al., 2010; Garrido-Gil et al., 2013b). Interestingly, the labeling for prorenin, AT1 and AT2 receptors was not only located at the cell surface but also intracellularly in dopaminergic neurons and glial cells (Garrido-Gil et al., 2013b). Therefore, our observations support the existence of an intracellular/intracrine RAS in neurons, and particularly in dopaminergic neurons, as previously suggested for other cell types (Baker et al., 2004; Kumar et al., 2007, 2009).

\section{INCREASED LOCAL RAS ACTIVITY ENHANCES DOPAMINERGIC CELL VULNERABILITY: MECHANISMS INVOLVED}

In several recent studies, we used 6-OHDA and MPTP models of parkinsonism to study the possible role of the brain RAS in dopaminergic degeneration: the results suggest that enhanced levels of AII, via AT1 receptors, exacerbate dopaminergic cell death and may play a synergistic role in the pathogenesis and progression of PD. Recent experimental data from other laboratories also support the involvement of brain RAS in dopaminergic degeneration (Grammatopoulos et al., 2007; Zawada et al., 2011; Sonsalla et al., 2013). It was observed that AII increased the neurotoxic effect induced by low doses of dopaminergic neurotoxins, and that treatment with ACEIs (Lopez-Real et al., 2005; Muñoz et al., 2006; Sonsalla et al., 2013) or blockage of AT1 receptors (Rey et al., 2007; Rodriguez-Pallares et al., 2008; Joglar et al., 2009) led to significant reduction in the loss of dopaminergic neurons and levels of protein oxidation and lipid peroxidation induced by the neurotoxins (Sanchez-Iglesias et al., 2007). Interestingly, the neuronal loss was also reduced by inhibitors of NADPH-oxidase activation, which suggests that NADPH activation and NADPHderived ROS are involved in the AII-enhanced dopaminergic neuron death (Rey et al., 2007; Rodriguez-Pallares et al., 2008; Joglar et al., 2009). 
In peripheral tissues (see above) and brain (Benicky et al., 2009; Wright and Harding, 2013), abnormal upregulation of local AII induces OS damage and exacerbates inflammation. Oxidative stress and neuroinflammation (including microglial NADPHoxidase activation) constitute early components of dopaminergic cell death and both factors act synergistically with others to induce progression of PD (Gao et al., 2003; Wu et al., 2003; RodriguezPallares et al., 2007). In the substantia nigra, AII receptors and $\mathrm{NADPH}$-oxidase were observed in dopaminergic neurons and glial cells. Therefore, AII may also enhance dopaminergic degeneration through several mechanisms, as previously observed in the vessel wall (Figure 1). First, AII acts on neurons (i.e., resident cells) via AT1 receptors and stimulates production of low levels of intraneuronal ROS by activation of neuronal NADPH-oxidase. ROS act as second messengers in several signaling pathways, including those involved in triggering the inflammatory response and the migration of inflammatory cells into the lesioned area; NADPH-derived ROS also modulate neuronal levels of ROS by interacting with mitochondria-derived ROS and with ROS from other sources such as dopaminergic neurotoxins or activated microglia. Feed-forward cross-talk signaling between NADPH oxidase-derived ROS and mitochondria-derived ROS has been observed in several types of cells (Doughan et al., 2008; Wosniak et al., 2009). This interaction has recently been confirmed in a dopaminergic cell line treated with the neurotoxin $\mathrm{MPP}^{+}$and angiotensin (Zawada et al., 2011) and in our recent studies with primary cultures of dopaminergic cells (Rodriguez-Pallares et al., 2009, 2012). Second, AII acts on microglia (i.e., inflammatory cells), in which NADPH oxidase activation produces high concentrations of ROS, which are released extracellularly and affect neurons; AII also produces low levels of microglial intracellular ROS, which act as a second messenger in several microglial signaling pathways involved in the inflammatory response (Babior, 2004; Qin et al., 2004). We have recently shown that activation of the microglial RhoA/ROCK pathway (Villar-Cheda et al., 2012a; Borrajo et al., 2014b), release of microglial TNF- $\alpha$ (Borrajo et al., 2014a), and altered iron homeostasis (Garrido-Gil et al., 2013a) are involved in the enhancing effect of AII/AT1 activation on the microglial response and dopaminergic degeneration. Activation of peroxisome proliferator-activated receptor gamma (PPAR- $\gamma$ ) also mediates the neuroprotective and antiinflammatory effects of AT1 receptor inhibition (Garrido-Gil et al., 2012).

\section{FACTORS THAT MAY INCREASE RAS ACTIVITY IN THE NIGROSTRIATAL DOPAMINERGIC SYSTEM}

Interaction between dopamine and angiotensin was initially suggested to occur in the basal ganglia because acute administration of AII directly into the striatum (via microdialysis probes) induced an increase in extracellular levels of dopamine in normal rats, which was blocked by co-administration of AT1 receptor antagonists (Mendelsohn et al., 1993; Brown et al., 1996). This suggested that AII, via AT1 receptors, facilitates the release of dopamine. However, acute or chronic administration of AT1 receptor antagonists alone did not alter striatal dopamine levels (Dwoskin et al., 1992; Mendelsohn et al., 1993; Brown et al., 1996; Jenkins, 2008). This was attributed to possible compensatory mechanisms, which we have recently investigated in normal rats and dopaminergic denervated rats (Dominguez-Meijide et al., 2014). Therefore, it seems reasonable to assume that a decrease in dopaminergic activity may induce a compensatory increase in RAS activity to increase striatal dopamine. However, if the dopaminergic system is impaired (e.g., in the initial stages of dopaminergic lesions or aging), normal dopaminergic levels cannot be reached and the resulting overactivation of the RAS may exacerbate the microglial inflammatory response and produce OS, leading to progression of dopaminergic vulnerability and neurodegeneration. In a series of recent studies, we have confirmed that a decrease in dopaminergic activity induces compensatory upregulation of local RAS function in both dopaminergic neurons and glia (Figure 1). It is known that both angiotensin (Rodriguez-Pallares et al., 2004, 2008; Joglar et al., 2009; GarridoGil et al., 2013b) and dopamine (Miyazaki et al., 2004; Färber et al., 2005) receptors are located in neurons, microglia and astrocytes. In the nigrostriatal system, we observed that dopamine depletion induced a significant increase in AT1 and AT2 receptor expression, and NADPH-oxidase complex activity, which decreased as dopamine function was restored (Villar-Cheda et al., 2010). More recently, we investigated the possible interactions between angiotensin and dopamine receptors in D1-, D2-, and AT1-deficient mice, as well as mice over-expressing D2 receptors. A counter-regulatory mechanism between dopamine and angiotensin receptors was observed in the striatum and substantia nigra of these mice (Villar-Cheda et al., 2014). A similar interaction between dopamine and angiotensin receptors has recently been demonstrated in peripheral tissues, particularly in relation to the regulation of renal sodium excretion and cardiovascular function (Zeng et al., 2006; Khan et al., 2008; Gildea, 2009; Padia et al., 2012).

Other factors may induce an increase in RAS activity independently or before the loss of dopamine (Figure 1). It is known that dopaminergic neurotoxins such as $\mathrm{MPP}^{+}$can act directly on astrocytes to induce an increase in production of proinflammatory factors (Henze et al., 2005; Block et al., 2007); astrocytes are the main source of angiotensinogen/angiotensin (Stornetta et al., 1988; Milsted et al., 1990), which may then act on neurons and microglial cells as indicated above. A loss of estrogen and other mechanisms that inhibit the neuroinflammatory response may also induce RAS activation and lead to an increase in dopaminergic neuron vulnerability as detailed below.

\section{DOPAMINERGIC VULNERABILITY IN AGING, MENOPAUSE AND BRAIN HYPOPERFUSION. ROLE OF RAS HYPERACTIVITY}

In recent studies, we investigated whether enhanced RAS activity in the nigra may be involved in the increased vulnerability of dopaminergic neurons to degeneration observed in aging, postmenopause or chronic cerebral hypoperfusion. Several studies have shown that normal aging is associated with a proinflammatory and pro-oxidant state that may favor an exaggerated response to injury and degenerative diseases (Csiszar et al., 2003; Ungvari et al., 2004; Choi et al., 2010). We have confirmed that, in aged male rats, aging enhances levels of neuroinflammation, OS markers and dopaminergic cell death induced by dopaminergic neurotoxins. The nigral RAS is involved in these effects, and levels 


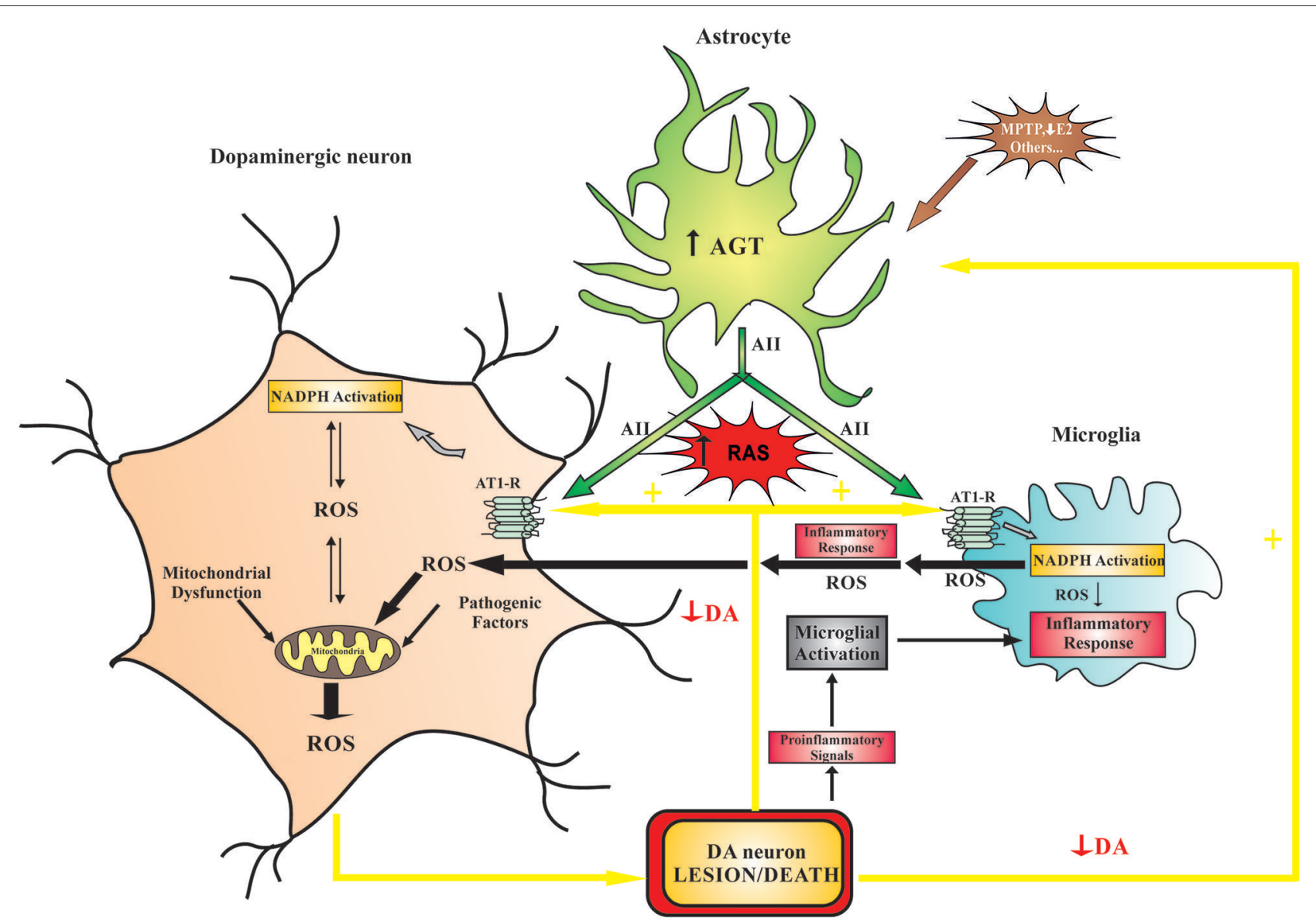

FIGURE 1 | Model of the role that brain RAS plays in dopaminergic cell vulnerability. Different pathogenic factors (e.g., mitochondrial dysfunction, aging-related changes, neurotoxins, etc.) may initiate dopaminergic lesions and diminish dopaminergic function, which leads to increased RAS activation and progression of the dopaminergic degeneration. Furthermore, neurotoxins and proinflammatory factors may act directly on astrocytes and induce an increase in ANG/All production, which leads to an increase in RAS activity and dopaminergic vulnerability. In dopaminergic neurons, increased RAS activity (via AT1 receptors) increases NADPH-oxidase activity, which enhances intraneuronal ROS production (in an interaction with mitochondria) and pro-inflammatory signals. In microglial cells, increased RAS activity stimulates the NADPH-oxidase complex, which enhances the inflammatory response, promoting extracellular release of high levels of ROS, activation of ROCK, and the release of cytokines and different neurotoxic factors. ANG,

angiotensinogen; All, angiotensin II; AT1, angiotensin type I receptors; DA, dopamine; E2, estrogen; NADPH, NADPH-oxidase complex; RAS,

renin-angiotensin system; ROCK, Rho-associated kinase; ROS, reactive oxygen species. of neuroinflammation, OS markers and dopaminergic cell death are reduced by treatment with the AT1 antagonist candesartan (Villar-Cheda et al., 2012b, 2014). Numerous studies in animal models and humans have shown aging-related loss of striatal D2 and D1 receptors (Wang et al., 1998; Ishibashi et al., 2009; Rieckmann et al., 2011), and that the dopaminergic system is altered during normal aging (Kubis et al., 2000; Collier et al., 2007). Therefore, the RAS upregulation that we observed in aged rats may be part of the compensatory changes related to decreased levels of dopamine or dopamine receptors (Villar-Cheda et al., 2012b, 2014). However, other factors may also be involved (CruzMuros et al., 2007, 2009), as aging has been shown to be associated with overactivation of RAS in a number of tissues (Thompson et al., 2000; Min et al., 2009; Cassis et al., 2010). Thus, the upregulation of AT1 receptors observed in aged rats may be part of the compensatory changes related to changes in the dopaminergic system; however, the compensatory upregulation of AT2 receptors observed in young rats with similar changes in the dopaminergic system was not observed in aged rats.

Menopause has also been identified as a prominent risk factor for PD. Numerous experimental studies have shown that estrogen exerts protective effects against dopaminergic cell degeneration (Leranth et al., 2000; Callier et al., 2002). The anti-inflammatory effects of estrogen play a major role in the neuroprotective effects (Suzuki et al., 2007; Vegeto et al., 2008), although direct antiapoptotic (Das et al., 2011; Brendel et al., 2013) and trophic (López-Martín et al., 1999; Campos et al., 2012) effects on neurons have also been suggested. A number of epidemiological studies have also reported that the incidence and prevalence of PD is higher in postmenopausal women and men than in premenopausal women of similar age (Currie et al., 2004; Ragonese et al., 2006a,b). However, some reported effects of estrogen replacement therapy are controversial (Shulman, 2002; Popat et al., 2005), and the age and duration of lack of estrogen 
in women receiving the treatment appear to be major factors in the discrepancies. Interestingly, estrogen-induced regulation of the RAS mediates beneficial effects of estrogen in several tissues (Nickenig et al., 1998; Dean et al., 2005; Chen et al., 2008), and interactions between estrogen and AII receptors have also been observed (Liu et al., 2002; Tsuda et al., 2005; Xue et al., 2007; Hoshi-Fukushima et al., 2008). In several recent studies we have observed that the lack of estrogen increases RAS activity in the substantia nigra in females (Rodriguez-Perez et al., 2010, 2011, 2012). We compared young ovariectomized rats (i.e., early surgical menopause) with aged rats (i.e., natural menopause). Both groups of menopausal rats showed increased RAS activity. However, estrogen therapy significantly reduced 6-OHDAinduced dopaminergic cell loss in young rats but not in aged rats, suggesting that other factors are involved in aged females. Interestingly, treatment with the AT1 antagonist candesartan significantly reduced dopaminergic neuron loss in both groups of menopausal rats (Rodriguez-Perez et al., 2012).

Dopaminergic cell loss and signs parkinsonism have been observed in elderly people without PD (almost 40\%; Buchman et al., 2012), and presynaptic dopaminergic function is reduced in most patients with vascular parkinsonism (Zijlmans et al., 2007), suggesting an interaction between aging-related cerebrovascular disease/brain hypoperfusion and dopaminergic degeneration. This was confirmed in a recent study with animal models of chronic brain hypoperfusion (Rodriguez-Perez et al., 2013), in which we have shown that chronic hypoperfusion increases dopaminergic cell death by enhancing the deleterious effects of other factors (such as low doses of dopaminergic neurotoxins). This suggests that hypoperfusion derived from aging and/or vascular disease may increase the risk of development of parkinsonism. The mechanistic links between hypoperfusion/vascular disease and neurodegeneration are unknown. However, chronic hypoperfusion led to increased expression of inflammatory markers such as IL-1 $\beta$ and increased levels of OS markers such as NADPH activity (Rodriguez-Perez et al., 2013), which have been shown to be involved in the progression of dopaminergic cell death in animal models of PD and in PD patients (Wu et al., 2003; Koprich et al., 2008). Interestingly, these changes were accompanied by increased RAS activity in the substantia nigra, and they were inhibited by chronic treatment with the AT1 receptor antagonist candesartan (Rodriguez-Perez et al., 2013).

\section{ACKNOWLEDGMENTS}

The work was supported by Spanish Ministry of Science and Innovation, Spanish Ministry of Health (RD12/0019/0020 and CIBERNED), Galician Government (XUGA) and European Regional Development Fund (FEDER).

\section{REFERENCES}

Allen, A. M., MacGregor, D. P., Chai, S. Y., Donnan, G. A., Kaczmarczyk, S., Richardson, K., et al. (1992). Angiotensin II receptor binding associated with nigrostriatal dopaminergic neurons in human basal ganglia. Ann. Neurol. 32, 339-344. doi: 10.1002/ana.410320306

Babior, B. (1999). NADPH oxidase: an update. Blood 93, 1464-1476.

Babior, B. M. (2004). NADPH oxidase. Curr. Opin. Immunol. 16, 42-47. doi: 10. 1016/j.coi.2003.12.001
Baker, K. M., Chernin, M. I., Schreiber, T., Sanghi, S., Haiderzaidi, S., Booz, G. W., et al. (2004). Evidence of a novel intracrine mechanism in angiotensin II-induced cardiac hypertrophy. Regul. Pept. 120, 5-13. doi: 10.1016/j.regpep. 2004.04.004

Benicky, J., Sánchez-Lemus, E., Pavel, J., and Saavedra, J. M. (2009). Antiinflammatory effects of angiotensin receptor blockers in the brain and the periphery. Cell. Mol. Neurobiol. 29, 781-792. doi: 10.1007/s10571-009-9368-4

Block, M. L., Zecca, L., and Hong, J. S. (2007). Microglia-mediated neurotoxicity: uncovering the molecular mechanisms. Nat. Rev. Neurosci. 8, 57-69. doi: 10. 1038/nrn2038

Borrajo, A., Rodriguez-Perez, A. I., Diaz-Ruiz, C., Guerra, M. J., and LabandeiraGarcia, J. L. (2014a). Microglial TNF- $\alpha$ mediates enhancement of dopaminergic degeneration by brain angiotensin. Glia 62, 145-157. doi: 10.1002/glia.22595

Borrajo, A., Rodriguez-Perez, A. I., Villar-Cheda, B., Guerra, M. J., and LabandeiraGarcia, J. L. (2014b). Inhibition of the microglial response is essential for the neuroprotective effects of Rho-kinase inhibitors on MPTP-induced dopaminergic cell death. Neuropharmacology 85C, 1-8. doi: 10.1016/j.neuropharm.2014. 05.021

Brendel, A., Felzen, V., Morawe, T., Manthey, D., and Behl, C. (2013). Differential regulation of apoptosis-associated genes by estrogen receptor alpha in human neuroblastoma cells. Restor. Neurol. Neurosci. 31, 199-211. doi: 10.3233/RNN120272

Brown, D. C., Steward, L. J., Ge, J., and Barnes, N. M. (1996). Ability of angiotensin II to modulate striatal dopamine release via the AT1 receptor in vitro and in vivo. Br. J. Pharmacol. 118, 414-420. doi: 10.1111/j.1476-5381.1996.tb15418.x

Brownfield, M. S., Reid, I. A., Ganten, D., and Ganong, W. F. (1982). Differential distribution of immunoreactive angiotensin and angiotensinconverting enzyme in rat brain. Neuroscience 7, 1759-1769. doi: 10.1016/03064522(82)90033-1

Buchman, A. S., Shulman, J. M., Nag, S., Leurgans, S. E., Arnold, S. E., Morris, M. C., et al. (2012). Nigral pathology and parkinsonian signs in elders without Parkinson disease. Ann. Neurol. 71, 258-266. doi: 10.1002/ana.22588

Cai, H. (2005). NAD(P)H oxidase-dependent self-propagation of hydrogen peroxide and vascular disease. Circ. Res. 96, 818-822. doi: 10.1161/01.res.0000163631. 07205.fb

Callier, S., Le Saux, M., Lhiaubet, A. M., Di Paolo, T., Rostène, W., and Pelaprat, D. (2002). Evaluation of the protective effect of oestradiol against toxicity induced by 6-hydroxydopamine and 1-methyl-4-phenylpyridinium ion (MPP+) towards dopaminergic mesencephalic neurones in primary culture. J. Neurochem. 80, 307-316. doi: 10.1046/j.0022-3042.2001.00693.x

Campos, F. L., Cristovão, A. C., Rocha, S. M., Fonseca, C. P., and Baltazar, G. (2012). GDNF contributes to oestrogen-mediated protection of midbrain dopaminergic neurones. J. Neuroendocrinol. 24, 1386-1397. doi: 10.1111/j.1365-2826.2012. 02348.x

Cassis, P., Conti, S., Remuzzi, G., and Benigni, A. (2010). Angiotensin receptors as determinants of life span. Pflugers Arch. 459, 325-332. doi: 10.1007/s00424-0090725-4

Chabrashvili, T., Kitiyakara, C., Blau, J., Karber, A., Aslam, S., Welch, W. J., et al. (2003). Effect of Ang II type 1 and 2 receptors on oxidative stress, renal $\mathrm{NAD}(\mathrm{P}) \mathrm{H}$ oxidase and SOD expresion. Am. J. Physisiol. Regu. Integr. Comp. Physiol. 285, R117-R124. doi: 10.1152/ajpregu.00476.2002

Chai, S. Y., Mendelsohn, F. A. O., and Paxinos, G. (1987). Angiotensin converting enzyme in rat brain visualized by quantitative in vitro autoradiography. Neuroscience 20, 615-627. doi: 10.1016/0306-4522(87)90114-x

Chen, J., Yang, S., Hu, S., Choudhry, M. A., Bland, K. I., and Chaudry, I. H. (2008). Estrogen prevents intestinal inflammation after trauma-hemorrhage via downregulation of angiotensin II and angiotensin II subtype I receptor. Am. J. Physio. Gastrointest. Liver Physiol. 295, G1131-G1137. doi: 10.1152/ajpgi.90443. 2008

Choi, D. Y., Zhang, J., and Bing, G. (2010). Aging enhances the neuroinflammatory response and alpha-synuclein nitration in rats. Neurobiol. Aging 31, 1649-1653. doi: 10.1016/j.neurobiolaging.2008.09.010

Collier, T. J., Lipton, J., Daley, B. F., Palfi, S., Chu, Y., Sortwell, C., et al. (2007). Aging-related changes in the nigrostriatal dopamine system and the response to MPTP in nonhuman primates: diminished compensatory mechanisms as a prelude to parkinsonism. Neurobiol. Dis. 26, 56-65. doi: 10.1016/j.nbd.2006.11. 013

Cruz-Muros, I., Afonso-Oramas, D., Abreu, P., Barroso-Chinea, P., Rodríguez, M., González, M. C., et al. (2007). Aging of the rat mesostriatal system: differences 
between the nigrostriatal and the mesolimbic compartments. Exp. Neurol. 204, 147-161. doi: 10.1016/j.expneurol.2006.10.004

Cruz-Muros, I., Afonso-Oramas, D., Abreu, P., Pérez-Delgado, M. M., Rodríguez, M., and González-Hernández, T. (2009). Aging effects on the dopamine transporter expression and compensatory mechanisms. Neurobiol. Aging 30, 973-986. doi: 10.1016/j.neurobiolaging.2007.09.009

Csiszar, A., Ungvari, Z., Koller, A., Edwards, J. G., and Kaley, G. (2003). Aginginduced proinflammatory shift in cytokine expression profile in coronary arteries. FASEB J. 17, 1183-1185. doi: 10.1096/fj.02-1049fje

Cuadra, A. E., Shan, Z., Sumners, C., and Raizada, M. K. (2010). A current view of brain renin-angiotensin system: is the (pro)renin receptor the missing link? Pharmacol. Ther. 125, 27-38. doi: 10.1016/j.pharmthera.2009.07.007

Currie, L. J., Harrison, M. B., Trugman, J. M., Bennett, J. P., and Wooten, G. F. (2004). Postmenopausal estrogen use affects risk for Parkinson disease. Arch. Neurol. 61, 886-888. doi: 10.1001/archneur.61.6.886

Das, A., Smith, J. A., Gibson, C., Varma, A. K., Ray, S. K., and Banik, N. L. (2011). Estrogen receptor agonists and estrogen attenuate TNF- $\alpha$-induced apoptosis in VSC4.1 motoneurons. J. Endocrinol. 208, 171-182. doi: 10.1677/JOE-10-0338

Dean, S. A., Tan, J., O’Brien, E. R., and Leenen, F. H. (2005). 17beta-estradiol downregulates tissue angiotensin-converting enzyme and ANG II type 1 receptor in female rats. Am. J. Physiol. Regul. Integr. Comp. Physiol. 288, R759-R766. doi: 10. 1152/ajpregu.00595.2004

Dominguez-Meijide, A., Villar-Cheda, B., Garrido-Gil, P., Sierra-Paredes, G., Guerra, M. J., and Labandeira-Garcia, J. L. (2014). Effect of chronic treatment with angiotensin type 1 receptor antagonists on striatal dopamine levels in normal rats and in a rat model of Parkinson's disease treated with L-DOPA. Neuropharmacology 76(Pt. A), 156-168. doi: 10.1016/j.neuropharm.2013.07.016

Doughan, A. K., Harrison, D. G., and Dikalov, S. I. (2008). Molecular mechanisms of angiotensin II-mediated mitochondrial dysfunction: linking mitochondrial oxidative damage and vascular endothelial dysfunction. Circ. Res. 102, 488-496. doi: $10.1161 /$ circresaha.107.162800

Dwoskin, L. P., Jewell, A. L., and Cassis, L. A. (1992). DuP 753, a nonpeptide angiotensin II-1 receptor antagonist, alters dopaminergic function in rat striatum. Naunyn Schmiedebergs Arch. Pharmacol. 345, 153-159. doi: 10. 1007/bf00165730

Färber, K., Pannasch, U., and Kettenmann, H. (2005). Dopamine and noradrenaline control distinct functions in rodent microglial cells. Mol. Cell. Neurosci. 29, 128-138. doi: 10.1016/j.mcn.2005.01.003

Ganong, W. F. (1994). Origin of the angiotensin II secreted by cells. Proc. Soc. Exp. Biol. Med. 205, 213-219. doi: 10.3181/00379727-205-43699a

Gao, H. M., Liu, B., Zhang, W., and Hong, J. S. (2003). Critical role of microglial NADPH oxidase-derived free radicals in the in vitro MPTP model of Parkinson's disease. FASEB J. 17, 1954-1956. doi: 10.1096/fj.03-0109fje

Garrido-Gil, P., Joglar, B., Rodriguez-Perez, A. I., Guerra, M. J., and LabandeiraGarcia, J. L. (2012). Involvement of PPAR- $\gamma$ in the neuroprotective and antiinflammatory effects of angiotensin type 1 receptor inhibition: effects of the receptor antagonist telmisartan and receptor deletion in a mouse MPTP model of Parkinson's disease. J. Neuroinflammation 9:38. doi: 10.1186/1742-2094-9-38

Garrido-Gil, P., Rodriguez-Pallares, J., Dominguez-Meijide, A., Guerra, M. J., and Labandeira-Garcia, J. L. (2013a). Brain angiotensin regulates iron homeostasis in dopaminergic neurons and microglial cells. Exp. Neurol. 250, 384-396. doi: 10.1016/j.expneurol.2013.10.013

Garrido-Gil, P., Valenzuela, R., Villar-Cheda, B., Lanciego, J. L., and LabandeiraGarcia, J. L. (2013b). Expression of angiotensinogen and receptors for angiotensin and prorenin in the monkey and human substantia nigra: an intracellular renin-angiotensin system in the nigra. Brain Struct. Funct. 218, 373-388. doi: 10.1007/s00429-012-0402-9

Gildea, J. J. (2009). Dopamine and angiotensin as renal counterregulatory systems controlling sodium balance. Curr. Opin. Nephrol. Hypertens. 18, 28-32. doi: 10. 1097/MNH.0b013e32831a9e0b

Grammatopoulos, T. N., Jones, S. M., Ahmadi, F. A., Hoover, B. R., Snell, L. D., Skoch, J., et al. (2007). Angiotensin type 1 receptor antagonist losartan, reduces MPTP-induced degeneration of dopaminergic neurons in substantia nigra. Mol. Neurodegener. 2:1. doi: 10.1186/1750-1326-2-1

Griendling, K. K., Sorescu, D., and Ushio-Fukai, M. (2000). NAD(P)H oxidase: role in cardiovascular biology and disease. Circ. Res. 86, 494-501. doi: 10.1161/01. RES.86.5.494

Henze, C., Hartmann, A., Lescot, T., Hirsch, E. C., and Michel, P. P. (2005). Proliferation of microglial cells induced by 1-methyl-4-phenylpyridinium in mesencephalic cultures results from an astrocyte-dependent mechanism: role of granulocyte macrophage colony-stimulating factor. J. Neurochem. 95, 10691077. doi: 10.1111/j.1471-4159.2005.03416.x

Hermann, K., McDonald, W., Unger, T., Lang, R. E., and Ganten, D. (1984). Angiotensin biosynthesis and concentrations in brain of normotensive and hypertensive rats. J. Physiol. (Paris) 79, 471-480.

Hoogwerf, B. J. (2010). Renin-angiotensin system blockade and cardiovascular and renal protection. Am. J. Cardiol. 105(Suppl. 1), 30A-35A. doi: 10.1016/j. amjcard.2009.10.009

Hoshi-Fukushima, R., Nakamoto, H., Imai, H., Kanno, Y., Ishida, Y., Yamanouchi, Y., et al. (2008). Estrogen and angiotensin II interactions determine cardio-renal damage in Dahl salt-sensitive rats with heart failure. Am. J. Nephrol. 28, 413-423. doi: $10.1159 / 000112806$

Ishibashi, K., Ishii, K., Oda, K., Kawasaki, K., Mizusawa, H., and Ishiwata, K. (2009). Regional analysis of age-related decline in dopamine transporters and dopamine D2-like receptors in human striatum. Synapse 63, 282-290. doi: 10.1002/syn. 20603

Iwanami, J., Mogi, M., Tsukuda, K., Min, L. J., Sakata, A., Jing, F., et al. (2010). Low dose of telmisartan prevents ischemic brain damage with peroxisome proliferator-activated receptor-gamma activation in diabetic mice. J. Hypertens. 28, 1730-1737. doi: 10.1097/HJH.0b013e32833a551a

Jenkins, T. A. (2008). Effect of angiotensin-related antihypertensives on brain neurotransmitter levels in rats. Neurosci. Lett. 444, 186-189. doi: 10.1016/j. neulet.2008.08.021

Joglar, B., Rodriguez-Pallares, J., Rodríguez-Perez, A. I., Rey, P., Guerra, M. J., and Labandeira-Garcia, J. L. (2009). The inflammatory response in the MPTP model of Parkinson's disease is mediated by brain angiotensin: relevance to progression of the disease. J. Neurochem. 109, 656-669. doi: 10.1111/j.14714159.2009.05999.x

Jones, E. S., Vinh, A., McCarthy, C. A., Gaspari, T. A., and Widdop, R. E. (2008). AT2 receptors: functional relevance in cardiovascular disease. Pharmacol. Ther. 120, 292-316. doi: 10.1016/j.pharmthera.2008.08.009

Kehoe, P. G., and Wilcock, G. K. (2007). Is inhibition of the renin-angiotensin system a new treatment option for Alzheimer's disease? Lancet Neurol. 6, 373378. doi: 10.1016/s1474-4422(07)70077-7

Kerr, D. S., Bevilaqua, L. R., Bonini, J. S., Rossato, J. I., Köhler, C. A., Medina, J. H., et al. (2005). Angiotensin II blocks memory consolidation through an AT2 receptor-dependent mechanism. Psychopharmacology (Berl) 179, 529-535. doi: 10.1007/s00213-004-2074-5

Khan, F., Spicarová, Z., Zelenin, S., Holtbäck, U., Scott, L., and Aperia, A. (2008). Negative reciprocity between angiotensin II type 1 and dopamine D1 receptors in rat renal proximal tubule cells. Am. J. Physiol. Renal Physiol. 295, F1110F1116. doi: 10.1152/ajprenal.90336.2008

Koprich, J. B., Reske-Nielsen, C., Mithal, P., and Isacson, O. (2008). Neuroinflammation mediated by IL-1beta increases susceptibility of dopamine neurons to degeneration in an animal model of Parkinson's disease. J. Neuroinflammation 5:8. doi: 10.1186/1742-2094-5-8

Kubis, N., Faucheux, B. A., Ransmayr, G., Damier, P., Duyckaerts, C., Henin, D., et al. (2000). Preservation of midbrain catecholaminergic neurons in very old human subjects. Brain 123, 366-373. doi: 10.1093/brain/123.2.366

Kumar, A., Rassoli, A., and Raizada, M. K. (1988). Angiotensinogen gene expression in neuronal and glial cells in primary cultures of rat brain. J. Neurosci. Res. 19, 287-290. doi: 10.1002/jnr.490190302

Kumar, R., Singh, V. P., and Baker, K. M. (2007). The intracellular reninangiotensin system: a new paradigm. Trends Endocrinol. Metab. 18, 208-214. doi: 10.1016/j.tem.2007.05.001

Kumar, R., Singh, V. P., and Baker, K. M. (2009). The intracellular reninangiotensin system in the heart. Curr. Hypertens. Rep. 11, 104-110. doi: 10. 1007/s11906-009-0020-y

Leranth, C., Roth, R. H., Elsworth, J. D., Naftolin, F., Horvath, T. L., and Redmond, D. E. Jr. (2000). Estrogen is essential for maintaining nigrostriatal dopamine neurons in primates: implications for Parkinson's disease and memory. J. Neurosci. 20, 8604-8609.

Lev-Ran, A., and Porta, M. (2005). Salt and hypertension: a phylogenetic perspective. Diabetes Metab. Res. Rev. 21, 118-131. doi: 10.1002/dmrr.539

Liu, H. W., Iwai, M., Takeda-Matsubara, Y., Wu, L., Li, J. M., Okumura, M., et al. (2002). Effect of estrogen and AT1 receptor blocker on neointima formation. Hypertension 40, 451-457. doi: 10.1161/01.hyp.0000033465.65 961.07 
López-Martín, E., Caruncho, H. J., Rodríguez-Pallares, J., Guerra, M. J., and Labandeira-García, J. L. (1999). Striatal dopaminergic afferents concentrate in GDNF-positive patches during development and in developing intrastriatal striatal grafts. J. Comp. Neurol. 406, 199-206. doi: 10.1002/(sici)10969861(19990405)406:2<199::aid-cne5>3.0.co;2-z

Lopez-Real, A., Rey, P., Soto-Otero, R., Mendez-Alvarez, E., and LabandeiraGarcia, J. L. (2005). Angiotensin-converting enzyme inhibitors reduce oxidative stress and protect dopaminergic neurons in a 6-hydroxydopamine rat model of parkinsonism. J. Neurosci. Res. 81, 865-873. doi: 10.1002/jnr.20598

Lou, M., Blume, A., Zhao, Y., Gohlke, P., Deuschl, G., Herdegen, T., et al. (2004). Sustained blockade of brain AT1 receptors before and after focal cerebral ischemia alleviates neurologic deficits and reduces neuronal injury, apoptosis and inflammatory responses in the rat. J. Cereb. Blood Flow Metab. 24, 536-547. doi: 10.1097/00004647-200405000-00008

Maul, B., Krause, W., Panlow, K., Becker, M., Gembardt, F., Alenina, N., et al. (2005). Central angiotensin II controls alcohol consumption via its AT1 receptor. FASEB J. 19, 1474-1481. doi: 10.1096/fj.05-3742com

Mendelsohn, F. A., Jenkins, T. A., and Berkovic, S. F. (1993). Effects of angiotensin II on dopamine and serotonin turnover in the striatum of conscious rats1993. Brain Res. 613, 221-229. doi: 10.1016/0006-8993(93)90902-y

Milsted, A., Barna, B. P., Ransohoff, R. M., Brosnihan, K. B., and Ferrario, C. M. (1990). Astrocyte cultures derived from human brain tissue express angiotensinogen mRNA. Proc. Natl. Acad. Sci. U S A 87, 5720-5723. doi: 10. 1073/pnas.87.15.5720

Min, L. J., Mogi, M., Iwai, M., and Horiuchi, M. (2009). Signaling mechanisms of angiotensin II in regulating vascular senescence. Ageing Res. Rev. 8, 113-121. doi: 10.1016/j.arr.2008.12.002

Miyazaki, I., Asanuma, M., Diaz-Corrales, F. J., Miyoshi, K., and Ogawa, N. (2004). Direct evidence for expression of dopamine receptors in astrocytes from basal ganglia. Brain Res. 1029, 120-123. doi: 10.1016/j.brainres.2004.09.014

Mogi, M., and Horiuchi, M. (2009). Effects of angiotensin II receptor blockers on dementia. Hypertens. Res. 32, 738-740. doi: 10.1038/hr.2009.110

Muñoz, A., Rey, P., Guerra, M. J., Mendez-Alvarez, E., Soto-Otero, R., and Labandeira-Garcia, J. L. (2006). Reduction of dopaminergic degeneration and oxidative stress by inhibition of angiotensin converting enzyme in a MPTP model of parkinsonism. Neuropharmacology 51, 112-120. doi: 10.1016/j. neuropharm.2006.03.004

Münzel, T., and Keany, J. F. (2001). Are ACE inhibitors a "magic bullet" against oxidative stress? Circulation 104, 1571-1577. doi: 10.1161/hc3801. 095585

Nickenig, G., Bäumer, A. T., Grohè, C., Kahlert, S., Strehlow, K., Rosenkranz, S., et al. (1998). Estrogen modulates AT1 receptor gene expression in vitro and in vivo. Circulation 97, 2197-2201. doi: 10.1161/01.cir.97.22.2197

Noh, K. M., and Koh, J. Y. (2000). Induction and activation by zinc of NADPH oxidase in cultured cortical neurons and astrocytes. J. Neurosci. 20, RC111RC115.

Okamura, A., Rakugi, H., Ohishi, M., Yanagitani, Y., Takiuchi, S., Moriguchi, K., et al. (1999). Upregulation of renin-angiotensin system during differentiation of monocytes to macrophages. J. Hypertens. 17, 537-545. doi: 10.1097/00004872199917040-00012

Oro, C., Qian, H., and Thomas, W. G. (2007). Type 1 angiotensin receptor pharmacology: signaling beyond G proteins. Pharmacol. Ther. 113, 210-226. doi: 10.1016/j.pharmthera.2006.10.001

Padia, S. H., Kemp, B. A., Howell, N. L., Keller, S. R., Gildea, J. J., and Carey, R. M. (2012). Mechanisms of dopamine D(1) and angiotensin type 2 receptor interaction in natriuresis. Hypertension 59, 437-445. doi: 10 . 1161/HYPERTENSIONAHA.111.184788

Phillips, M. I., and de Oliveira, E. M. (2008). Brain renin angiotensin in disease. J. Mol. Med. (Berl) 86, 715-722. doi: 10.1007/s00109-008-0331-5

Platten, M., Youssef, S., Hur, E. M., Ho, P. P., Han, M. H., Lanz, T. V., et al. (2009). Blocking angiotensin-converting enzyme induces potent regulatory $\mathrm{T}$ cells and modulates TH1- and TH17-mediated autoimmunity. Proc. Natl. Acad. Sci. U S A 106, 14948-14953. doi: 10.1073/pnas.0903958106

Popat, R. A., Van Den Eeden, S. K., Tanner, C. M., McGuire, V., Bernstein, A. L., Bloch, D. A., et al. (2005). Effect of reproductive factors and postmenopausal hormone use on the risk of Parkinson disease. Neurology 65, 383-390. doi: 10. 1212/01.wnl.0000171344.87802.94

Qin, L., Liu, Y., Wang, T., Wei, S. J., Block, M. L., Wilson, B., et al. (2004). NADPH oxidase mediates lipopolysaccharide-induced neurotoxicity and proinflammatory gene expression in activated microglia. J. Biol. Chem. 279, 1415-1421. doi: 10.1074/jbc.m307657200

Quinlan, J. T., and Phillips, M. I. (1981). Immunoreactivity for angiotensin IIlike peptide in the human brain. Brain Res. 205, 212-218. doi: 10.1016/00068993(81)90735-6

Ragonese, P., D’Amelio, M., and Savettieri, G. (2006b). Implications for estrogens in Parkinson's disease: an epidemiological approach. Ann. N Y Acad. Sci. 1089, 373-382. doi: 10.1196/annals.1386.004

Ragonese, P., D’Amelio, M., Callari, G., Salemi, G., Morgante, L., and Savettieri, G. (2006a). Age at menopause predicts age at onset of Parkinson's disease. Mov. Disord. 21, 2211-2214. doi: 10.1002/mds.21127

Re, R. N. (2004). Tissue renin angiotensin systems. Med. Clin. North Am. 88, 19-38. doi: 10.1016/S0025-7125(03)00124-X

Rey, P., Lopez-Real, A., Sanchez-Iglesias, S., Muñoz, A., Soto-Otero, R., and Labandeira-Garcia, J. L. (2007). Angiotensin type-1-receptor antagonists reduce 6-hydroxydopamine toxicity for dopaminergic neurons. Neurobiol. Aging 28, 555-567. doi: 10.1016/j.neurobiolaging.2006.02.018

Rieckmann, A., Karlsson, S., Karlsson, P., Brehmer, Y., Fischer, H., Farde, L., et al. (2011). Dopamine D1 receptor associations within and between dopaminergic pathways in younger and elderly adults: links to cognitive performance. Cereb. Cortex 21, 2023-2032. doi: 10.1093/cercor/bhq266

Rodriguez-Perez, A. I., Dominguez-Meijide, A., Lanciego, J. L., Guerra, M. J., and Labandeira-Garcia, J. L. (2013). Dopaminergic degeneration is enhanced by chronic brain hypoperfusion and inhibited by angiotensin receptor blockage. Age (Dordr) 35, 1675-1690. doi: 10.1007/s11357-012-9470-2

Rodriguez-Pallares, J., Parga, J. A., Joglar, B., Guerra, M. J., and Labandeira-Garcia, J. L. (2009). The mitochondrial ATP-sensitive potassium channel blocker 5hydroxydecanoate inhibits toxicity of 6-hydroxydopamine on dopaminergic neurons. Neurotox. Res. 15, 82-95. doi: 10.1007/s12640-009-9010-8

Rodriguez-Pallares, J., Parga, J. A., Joglar, B., Guerra, M. J., and LabandeiraGarcia, J. L. (2012). Mitochondrial ATP-sensitive potassium channels enhance angiotensin-induced oxidative damage and dopaminergic neuron degeneration. Relevance for aging-associated susceptibility to Parkinson's disease. Age (Dordr) 34, 863-880. doi: 10.1007/s11357-011-9284-7

Rodriguez-Pallares, J., Parga, J. A., Muñoz, A., Rey, P., Guerra, M. J., and Labandeira-Garcia, J. L. (2007). Mechanism of 6-hydroxydopamine neurotoxicity: the role of $\mathrm{NADPH}$ oxidase and microglial activation in 6-hydroxydopamine-induced degeneration of dopaminergic neurons. J. Neurochem. 103, 145-156. doi: 10.1111/j.1471-4159.2007.04699.x

Rodriguez-Pallares, J., Quiroz, C. R., Parga, J. A., Guerra, M. J., and LabandeiraGarcia, J. L. (2004). Angiotensin II increases differentiation of dopaminergic neurons from mesencephalic precursors via angiotensin type 2 receptors. Eur. J. Neurosci. 20, 1489-1498. doi: 10.1111/j.1460-9568.2004.03621.x

Rodriguez-Pallares, J., Rey, P., Parga, J. A., Muñoz, A., Guerra, M. J., and Labandeira-Garcia, J. L. (2008). Brain angiotensin enhances dopaminergic cell death via microglial activation and NADPH-derived ROS. Neurobiol. Dis. 31, 58-73. doi: 10.1016/j.nbd.2008.03.003

Rodriguez-Perez, A. I., Valenzuela, R., Joglar, B., Garrido-Gil, P., Guerra, M. J., and Labandeira-Garcia, J. L. (2011). Renin angiotensin system and gender differences in dopaminergic degeneration. Mol. Neurodegener. 6:58. doi: 10. 1186/1750-1326-6-58

Rodriguez-Perez, A. I., Valenzuela, R., Villar-Cheda, B., Guerra, M. J., and Labandeira-Garcia, J. L. (2012). Different dopaminergic neuroprotection of hormonal replacement therapy in young and aged menopausal rats. Role of the brain angiotensin system. Brain 135, 124-138. doi: 10.1093/brain/awr320

Rodriguez-Perez, A. I., Valenzuela, R., Villar-Cheda, B., Guerra, M. J., Lanciego, J. L., and Labandeira-Garcia, J. L. (2010). Estrogen and angiotensin interaction in the substantia nigra. Relevance to postmenopausal Parkinson's disease. Exp. Neurol. 224, 517-526. doi: 10.1016/j.expneurol.2010.05.015

Ruiz-Ortega, M., Lorenzo, O., Ruperez, M., Suzuki, Y., and Egido, J. (2001). Proinflammatory actions of angiotensin II. Curr. Opin. Nephrol. Hypertens. 10, 321-329. doi: 10.1097/00041552-200105000-00005

Saab, Y. B., Gard, P. R., Yeoman, M. S., Mfarrej, B., El-Moalem, H., and Ingram, M. J. (2007). Renin-angiotensin-system gene polymorphisms and depression. Prog. Neuropsychopharmacol. Biol. Psychiatry 31, 1113-1118. doi: 10.1016/j. pnpbp.2007.04.002

Saavedra, J. M. (2005). Brain angiotensin II: new developments, unanswered questions and therapeutic opportunities. Cell. Mol. Neurobiol. 25, 485-512. doi: 10.1007/s10571-005-4011-5 
Saavedra, J. M. (2012). Angiotensin II AT(1) receptor blockers ameliorate inflammatory stress: a beneficial effect for the treatment of brain disorders. Cell. Mol. Neurobiol. 32, 667-681. doi: 10.1007/s10571-011-9754-6

Sanchez-Iglesias, S., Rey, P., Mendez-Alvarez, E., Labandeira-Garcia, J. L., and Soto-Otero, R. (2007). Time-course of brain oxidative damage caused by intrastriatal administration of 6-hydroxydopamine in a rat model of Parkinson's disease. Neurochem. Res. 32, 99-105. doi: 10.1007/s11064-0069232-6

Shulman, L. M. (2002). Is there a connection between estrogen and Parkinson's disease? Parkinsonism Relat. Disord. 8, 289-295. doi: 10.1016/s13538020(02)00014-7

Simonnet, G., Giorguieff-Chesselet, M. F., Carayon, A., Bioulac, B., Cesselin, F., Glowinski, J., et al. (1981). Angiotensin II and the nigrostriatal system. J. Physiol. 77, 71-79.

Sonsalla, P. K., Coleman, C., Wong, L. Y., Harris, S. L., Richardson, J. R., Gadad, B. S., et al. (2013). The angiotensin converting enzyme inhibitor captopril protects nigrostriatal dopamine neurons in animal models of parkinsonism. Exp. Neurol. 250, 376-383. doi: 10.1016/j.expneurol.2013.10.014

Stegbauer, J., Lee, D. H., Seubert, S., Ellrichmann, G., Manzel, A., Kvakan, H., et al. (2009). Role of the renin-angiotensin system in autoimmune inflammation of the central nervous system. Proc. Natl. Acad. Sci. U S A 106, 14942-14947. doi: 10.1073/pnas.0903602106

Stornetta, R. L., Hawelu-Johnson, C. L., Guyenet, P. G., and Lynch, K. R. (1988). Astrocytes synthesize angiotensinogen in brain. Science 242, 1444-1446. doi: 10. $1126 /$ science. 3201232

Suzuki, S., Brown, C. M., Dela Cruz, C. D., Yang, E., Bridwell, D. A., and Wise, P. M. (2007). Timing of estrogen therapy after ovariectomy dictates the efficacy of its neuroprotective and antiinflammatory actions. Proc. Natl. Acad. Sci. U S A 104 6013-6018. doi: 10.1073/pnas.0610394104

Suzuki, Y., Ruiz-Ortega, M., Lorenzo, O., Ruperez, M., Esteban, V., and Egido, J. (2003). Inflammation and angiotensin II. Int. J. Biochem. Cell Biol. 35, 881-900. doi: 10.1016/S1357-2725(02)00271-6

Thomas, W. G., Greenland, K. J., Shinkel, T. A., and Sernia, C. (1992). Angiotensinogen is secreted by pure rat neuronal cell cultures. Brain Res. 588, 191-200. doi: 10.1016/0006-8993(92)91575-y

Thompson, M. M., Oyama, T. T., Kelly, F. J., Kennefick, T. M., and Anderson, S. (2000). Activity and responsiveness of the renin-angiotensin system in the aging rat. Am. J. Physiol. Regul. Integr. Comp. Physiol. 279, R1787-R1794.

Touyz, R. M. (2004). Reactive oxygen species and angiotensin II signaling in vascular cells-implications in cardiovascular disease. Braz. J. Med. Biol. Res. 37, 1263-1273. doi: 10.1590/s0100-879x2004000800018

Tsuda, M., Iwai, M., Li, J. M., Li, H. S., Min, L. J., Ide, A., et al. (2005). Inhibitory effects of AT1 receptor blocker, olmesartan and estrogen on atherosclerosis via anti-oxidative stress. Hypertension 45, 545-551. doi: 10.1161/01.hyp. 0000157409.88971.fc

Unger, T., Chung, O., Csikos, T., Culman, J., Gallinat, S., Gohlke, P., et al. (1996). Angiotensin receptors. J. Hypertens. Suppl. 14, S95-S103.

Ungvari, Z., Csiszar, A., and Kaley, G. (2004). Vascular inflammation in aging. Herz 29, 733-740. doi: 10.1007/s00059-004-2625-x

Valenzuela, R., Barroso-Chinea, P., Villar-Cheda, B., Joglar, B., Muñoz, A., Lanciego, J. L., et al. (2010). Location of prorenin receptors in primate substantia nigra: effects on dopaminergic cell death. J. Neuropathol. Exp. Neurol. 69, 11301142. doi: 10.1097/NEN.0b013e3181fa0308

Vegeto, E., Benedusi, V., and Maggi, A. (2008). Estrogen anti-inflammatory activity in brain: a therapeutic opportunity for menopause and neurodegenerative diseases. Front. Neuroendocrinol. 29, 507-519. doi: 10.1016/j.yfrne.2008. 04.001

Villar-Cheda, B., Dominguez-Meijide, A., Joglar, B., Rodriguez-Perez, A. I., Guerra, M. J., and Labandeira-Garcia, J. L. (2012a). Involvement of microglial RhoA/Rho-Kinase pathway activation in the dopaminergic neuron death. Role of angiotensin via angiotensin type 1 receptors. Neurobiol. Dis. 47, 268-279. doi: 10.1016/j.nbd.2012.04.010

Villar-Cheda, B., Dominguez-Meijide, A., Valenzuela, R., Granado, N., Moratalla, R., and Labandeira-Garcia, J. L. (2014). Aging-related dysregulation of dopamine and angiotensin receptor interaction. Neurobiol. Aging 35, 17261738. doi: 10.1016/j.neurobiolaging.2014.01.017

Villar-Cheda, B., Rodríguez-Pallares, J., Valenzuela, R., Muñoz, A., Guerra, M. J., Baltatu, O. C., et al. (2010). Nigral and striatal regulation of angiotensin receptor expression by dopamine and angiotensin in rodents: implications for progression of Parkinson's disease. Eur. J. Neurosci. 32, 1695-1706. doi: 10. 1111/j.1460-9568.2010.07448.x

Villar-Cheda, B., Valenzuela, R., Rodriguez-Perez, A. I., Guerra, M. J., and Labandeira-Garcia, J. L. (2012b). Aging-related changes in the nigral angiotensin system enhances proinflammatory and pro-oxidative markers and 6-OHDA-induced dopaminergic degeneration. Neurobiol. Aging 33, 204.e1204.e11. doi: 10.1016/j.neurobiolaging.2010.08.006

von Bohlen und Halbach, O., and Albrecht, D. (2006). The CNS renin-angiotensin system. Cell Tissue Res. 326, 599-616. doi: 10.1007/s00441-006-0190-8

Wang, G., Anrather, J., Huang, J., Speth, R. C., Pickel, V., and Iadecola, C. (2004). NADPH oxidase contributes to angiotensin II signalling in the nucleus tractus solitarius. J. Neurosci. 24, 5516-5524. doi: 10.1523/jneurosci.1176-04.2004

Wang, Y., Chan, G. L., Holden, J. E., Dobko, T., Mak, E., Schulzer, M., et al. (1998). Age-dependent decline of dopamine D1 receptors in human brain: a PET study. Synapse 30, 56-61. doi: 10.1002/(sici)1098-2396(199809)30:1<56::aid-syn7>3. $0 . \mathrm{co} ; 2-\mathrm{j}$

Wosniak, J. Jr., Santos, C. X., Kowaltowski, A. J., and Laurindo, F. R. (2009). Crosstalk between mitochondria and NADPH oxidase: effects of mild mitochondrial dysfunction on angiotensin II-mediated increase in Nox isoform expression and activity in vascular smooth muscle cells. Antioxid. Redox Signal. 11, 1265-1278. doi: 10.1089/ars.2009.2392

Wright, J. W., and Harding, J. W. (2013). The brain renin-angiotensin system: a diversity of functions and implications for CNS diseases. Pflugers Arch. 465, 133151. doi: 10.1007/s00424-012-1102-2

Wu, D., Teisman, P., Tieu, K., Vila, M., Jackson-Lewis, V., Ischiropoulos, H., et al. (2003). NADPH oxidase mediates oxidative stress in the 1-methyl-4-phenyl1,2,3,6-tetrahydropyridine model of Parkinson's disease. Proc. Natl. Acad. Sci. U S A 100, 6145-6150. doi: 10.1073/pnas.0937239100

Xue, B., Pamidimukkala, J., Lubahn, D. B., and Hay, M. (2007). Estrogen receptoralpha mediates estrogen protection from angiotensin II-induced hypertension in conscious female mice. Am. J. Physiol. Heart Circ. Physiol. 292, H1770-H1776. doi: 10.1152/ajpheart.01011.2005

Yanagitani, Y., Rakugi, H., Okamura, A., Moriguchi, K., Takiuchi, S., Ohishi, M., et al. (1999). Angiotensin II type 1 receptor-mediated peroxide production in human macrophages. Hypertension 33, 335-339. doi: 10.1161/01.hyp.33.1.335

Zalba, G., San Jose, G., Moreno, M. U., Fortuño, M. A., Fortuño, A., Beaumont, F. J., et al. (2001). Oxidative stress in arterial hypertension. Role of NADPH oxidase. Hypertension 38, 1395-1399. doi: 10.1161/hy1201.099611

Zawada, W. M., Banninger, G. P., Thornton, J., Marriott, B., Cantu, D., Rachubinski, A. L., et al. (2011). Generation of reactive oxygen species in 1-methyl-4phenylpyridinium $(\mathrm{MPP}+)$ treated dopaminergic neurons occurs as an NADPH oxidase-dependent two-wave cascade. J. Neuroinflammation 8:129. doi: 10 . 1186/1742-2094-8-129

Zeng, C., Liu, Y., Wang, Z., He, D., Huang, L., Yu, P., et al. (2006). Activation of D3 dopamine receptor decreases angiotensin II type 1 receptor expression in rat renal proximal tubule cells. Circ. Res. 99, 494-500. doi: 10.1161/01.res. 0000240500.96746.ec

Zijlmans, J., Evans, A., Fontes, F., Katzenschlager, R., Gacinovic, S., Lees, A. J., et al. (2007). [123I] FP-CIT spect study in vascular parkinsonism and Parkinson's disease. Mov. Disord. 22, 1278-1285. doi: 10.1002/mds.21479

Conflict of Interest Statement: The authors declare that the research was conducted in the absence of any commercial or financial relationships that could be construed as a potential conflict of interest.

Received: 28 May 2014; accepted: 24 June 2014; published online: 08 July 2014. Citation: Labandeira-García JL, Garrido-Gil P, Rodriguez-Pallares J, Valenzuela R, Borrajo A and Rodríguez-Perez AI (2014) Brain renin-angiotensin system and dopaminergic cell vulnerability. Front. Neuroanat. 8:67. doi: 10.3389/fnana.2014. 00067

This article was submitted to the journal Frontiers in Neuroanatomy.

Copyright (c) 2014 Labandeira-García, Garrido-Gil, Rodriguez-Pallares, Valenzuela, Borrajo and Rodríguez-Perez. This is an open-access article distributed under the terms of the Creative Commons Attribution License (CC BY). The use, distribution or reproduction in other forums is permitted, provided the original author(s) or licensor are credited and that the original publication in this journal is cited, in accordance with accepted academic practice. No use, distribution or reproduction is permitted which does not comply with these terms. 